\title{
Critical Success Factors for Fundraising in Non-Profit Organisations: An Emerging Market Perspective
}

\author{
Baba Sayutia ${ }^{\text {, Livingstone Divine Caesar }}$. \\ ${ }^{a}$ Principal Security Officer, Ministry of National Security, Accra, Ghana \\ ${ }^{b}$ Research Scientist, CSIR-STEPRI Council for Scientific and Industrial Research, Accra, Ghana
}

\begin{abstract}
Non-profit organisations (NPOs) are key players in the socio-economic development of nations. This is evident in their proliferation at the local, national and international levels. Despite their increasing number, NPOs are confronted with diverse challenges which hinder their sustainability. This paper highlights some of the challenges confronting NPOs especially in the area of fundraising from an emerging market perspective. It examines some critical factors that drive success in fundraising among NPOs. Using a quantitative research design, a survey was sent to 200 randomly sampled participants with 130 responses received and the data analysed using Exploratory Factor Analysis and regression analysis. It emerged that having proper structures, coupled with credibility and accountability was critical to successful fundraising among NPOs in emerging markets. Also, NPOs need to carefully address a complex mix of external and internal issues to successfully raise funds for their operations. Prevailing economic conditions stood out as a key determinant of fundraising success. The study also revealed that the giving motive of fund givers was very important in affecting the relationships between economic conditions, internal resources of the entities, organisational strategy and success in fundraising.
\end{abstract}

Keywords: Non-profit organisations, emerging market, fundraising, critical success factors, accountability, economic conditions.

\section{Introduction}

With the onset of the $20^{\text {th }}$ Century, globalisation brought many challenges in its wake that could not readily be addressed by individual countries. This led to the proliferation of non-profit organisations (NPOs) to address the emerging global problems; and a response to the shortcomings of international treaties and organisations such as the World Trade Organisation (WTO) whose activities were perceived as being too centred on the interests of capitalist enterprises (Bhagwati, 2004). Hence NPOs sought to counterbalance this trend by highlighting humanitarian issues, developmental aid and sustainable development (Ahmed \& Potter, 2006). Today, it is probably impossible to determine the number of NPOs across the world due to the absence of a comprehensive and reliable database (Lewis \& Kanji, 2009). However, statistics from the USA show the existence of an estimated 2 million NPOs, most of them formed in the 
past 30 years (Adjei, Annor-Frempong \& Bosompem, 2016). In Africa, the number of NPOs is on the ascendancy.

As high-profile actors in the field of international development, NPOs critically contribute to the political and socio-economic development of countries (Mitlin, Hickey \& Bebbington, 2007). Using social intervention programs, they serve as policy advocates and service providers to vulnerable and less privileged individuals and communities. Structurally, NPOs may be large or small, bureaucratic or flexible; and seek to mobilize resources for a particular cause, or to otherwise serve the public in various pursuits. In Africa, and Ghana particularly, international and local NPOs, continue to contribute in various ways towards improving the living standards and quality of life of the underprivileged especially in rural communities (Unicef, 2011).

Given the role they play in society, NPOs require a great deal of monetary support and workable strategies to access funding either locally or from global sources. Fundraising is critical to the survival of NPOs as their sustainability greatly hinges on it. Okorley and Nkrumah (2012) contend that limited funding impedes the effective management and sustainability of NPOs given their dependability on donor funding, especially from external sources. Consequently, advancing practical and theoretical knowledge on factors that underpin effective fundraising is imperative (Lindahl \& Conley, 2002); especially for NPOs operating from emerging markets where access to steady funding is a key challenge. There are intra-organisational and extra-organisational factors that undermine successful fundraising. Investigating these might assist in comprehending the external forces and their influences on decision-making that occurs in the framework and development of fundraising organisations. This paper thus explores the multiplicity of factors that are critical to successful fundraising for NPOs from an emerging market perspective.

Also, a key gap exists when examining the current state of knowledge on fundraising and the complexity of factors connected to successful fundraising (Scott, 2014). For example, evidence-based approach to fundraising among NPOs in emerging markets is needed. Reliance on anecdotal evidence for fundraising strategies in emerging markets is no longer sustainable as the scramble for the limited available funds is getting keener (Nyanumba, 2018).

\subsection{Statement of the Problem}

Aside from the limited access to funding, NPOs in developing countries are also confronted with myriads of challenges in their bid to provide citizens with services respective governments fail to offer (Lekorwe \& Mpabanga, 2007). NPOs have been associated with several weaknesses including the lack of experienced manpower, short-range objectives, yielding to political influences and corruption (Brownell \& Basham, 2017; Taylor, Muwowo \& Phiri, 2018). Okorley and Nkrumah (2012) conclude that many NPOs in developing countries such as Ghana fold up within the first two years of their registration; and for those that survive, only a few remain active and functional. The worse affected are local NPOs.

This study attempts to investigate the link between internal and external factors affecting NPOs, and their fundraising success. The nexus between organisational structures and the fundraising success has been raised in the literature (Sargeant \& Jay, 2002) but not fully resolved. Practically, this paper makes a contribution to the dynamics of fundraising among NPOs from an 
emerging market perspective by examining the critical organisational factors that drive successful fundraising among NPOs.

Despite the glut of research on sustainability issues for NPOs, there appears to be a lacuna that this paper seeks to fill as previous studies have a developed economy bias (e.g. Edwards \& Hulme, 2014; Bendell, 2017). There is limited empirical work on these issues from the perspective of developing countries, particularly in Africa (Nah \& Saxton, 2013). Also, studies focused on Africa (such as Scott, 2014) used exploratory qualitative designs. This paper extends Scott (2014)'s a study using a quantitative approach to test factors applicable within the context of emerging market economies. The paper also uses giving motives as moderating construct to assess the nature of the relationship between organisational factors and fundraising success.

The rest of this paper is organized as follows. In Section 2 a review of the empirical literature on critical organisational factors and successful fundraising is provided. Also, this section focuses on a discussion of the theoretical framework of the study. Section 3 provides details on the methodology used for the paper. Section 4 presents the results of the study. In section 5, the discussions and industry implications of the paper are presented.

\section{Review of the extant literature}

\subsection{Challenges of fundraising}

Access to reliable funding sources is critical to the survival of NPOs; without which they are compelled to cancel their programmed activities. Consequently, many of them constantly work towards the mobilisation of resources to ensure the smooth execution of their respective mandates. Meanwhile, upsurge in the number of NPOs has resulted in increased competition for limited funds from donors (Batti, 2014). NPOs thus encounter many challenges (which may be external or internal) in their fundraising efforts which shrouds the future of their donor support in so much uncertainty. Innovative fundraising strategies are needed if NPOs must remain competitive given the stern competition for funding. Typically, most donors also face uncertainty in their operations, and this may affect the funds they may be willing to advance to NPOs (Batti, 2014).

\subsection{External Challenges of Fundraising}

The external challenges confronting NPOs are many. An example could be cited of change in priority of the donor. In practice, donors of NPOs usually dictate priorities for organisations that receive funds from them. This result in the organisations, shifting their focus to suit that of the donors or risk being disqualified to receive funds. This may be detrimental to the survival of the NPOs especially when changing donor priorities contradict the traditional motives for which the NPO was established (Parks, 2008). Another variant of this challenge is that certain organisational criteria used by donors undermine the fundraising efforts of some NPOs who may struggle to meet the said criteria. Hence, the conditions under which donors offer funding is constantly changing. For instance, preference is now given to government institutions; further compounding the fundraising challenges of non-governmental NPOs. These restrictions do not allow NGOs to acquire additional funding from prospective donors. 
Political interference is also among the external challenges confronting the fundraising efforts of NPOs. The policies of governments and political climate within the recipient countries have a significant effect on the ability of NPOs to secure external funds (Gyamfi, 2010). In times of political instability, for instance, donors hesitate to release funds to support organisations because they suspect the funds will not be used for the intended purposes. In Africa, strict government measures that seek to curtail the influence of NPOs makes it difficult for them to access external donor funding (Batti, 2014).

The good track record of organisations can be helpful for them to secure funds. There have been stories of gross embezzlement from some organisations that received funds from donors. As such, most donors are cautious in deciding to fund such organisations that are known not to offer value-for-money in their operations. Donors, therefore, see the track record of organisations as important in their decision to fund them. This is a major challenge for upcoming NPOs in emerging markets given that they lack the much-touted track record used by donors as reference (Batti, 2014; Britton, 2008).

\subsection{Internal Challenges}

There is pressure on NPOs to innovate and develop new solutions to the many fundraising challenges confronting them. Their efforts are however greeted by a complex web of internal challenges. For instance, many NPOs are unable to meet the accountability and transparency standards required by donors or the regulatory frameworks within their country of operation. Opaque governance systems in NPOs breeds mistrust and manifests as poor monitoring and control mechanisms misappropriation of funds and inadequate evaluation criteria. Also, many NPOs lack strategic direction as most strategic and operational plans developed are only intended for fundraising purposes but not meant to solve the problems of the society (Batti, 2014). Further, the inability of many NPOs to effectively communicate and brand themselves is undermining their ability to effectively raise funds (Batti, 2014; Najam, 1996).

\subsection{Theoretical Perspective}

Considering the competitiveness of raising funds for the sustainability of NPOs, relationship management and social exchange theories (Drezner, 2009) are considered as appropriate towards explaining the conceptual framework of the study. Drezner (2009) posits that these theories help to understand the dynamics of relationship development as a necessity for successful fundraising.

\subsubsection{Relationship Management Theory}

Relationship management theory has been linked to many studies on NPOs to understand the concept of fundraising. The theory helps in exploring the strategies that NPOs adopting to develop and build a workable relationship with stakeholders (Waters et al., 2011; Ki \& Hon, 2009). Ferguson (1984), reiterated that the paradigm of the relationship management theory draws on the creation, sustenance, and promotion of the long-term relationship between the organisation and its stakeholders, classified as donors, customers, or volunteers. This has necessitated the three aspects of relationship management to be considered in the fundraising 
activities of NPOs; Customer Relationship Management (Zheng, 2012) and Relationship Marketing (Sargeant, 2016).

CRM is widely applied in NPOs to increase its fundraising income (Bennett \& Sargeant, 2005). For instance, most NPOs are under intense pressure to adopt CRM to help secure funding for charitable activities, whereas some adopt the strategy to build benefit-reaping relationships with their donors (Bennett, 2005). It is an alternative strategy developed from the relationship marketing literature with a focus on the customer (Anderson et al., 2004). Zheng (2012) identified three important gaps which reveal that studies on the implementation of CRM in NPOs are still at the developing stage. Hence, there is a lack of sufficient empirical studies to establish the success factors that are critical to the applicability of CRM NPOs. Also, there is a paucity of studies investigating the challenges and barriers confronting the implementation and outcomes of CRM in NPOs.

Relationship marketing encompasses all the activities aimed at directing the establishment, development, and maintenance of relationships to foster successful rational exchange (Abubakar \& Mokhar, 2015; Morgan \& Hunt, 1994). Grönroos (2006) argued that exchange was the main aspect of traditional marketing which is currently not visible in relationship marketing. However, Abubakar and Mokhar (2015) assert that relationship marketing involves more than just exchange to include collaboration, trust, power balance and loyalty with commitment considered as its foundation. The suitability of relationship marketing to the activities of NPOs is explained by the constantly evolving and competitive nature of the environment in which they operate; as it is the strategy needed to stay in the competition of finding and keeping donors (Feuk, 2011). It emphasises the building of a long-term relationship through which NPOs could transition from a one-time fundraising transaction to a lifetime relationship with donors (Sargeant \& McKenzie, 1998).

\subsubsection{Social Exchange Theory}

Bennett (2005) posits that the premise of the relationship between organisations and their donors is built on exchange. Therefore, NPOs who can build long-term relationships with their donors get the opportunity to benefit from the relationship (Weir \& Hibbert, 2000). To achieve this objective, the social exchange theory emphasises collaboration, trust, power balance, loyalty and commitment in respect to the organisation's relationship with its donors and stakeholders (Perkins et al., 2009).

Some studies such as the one conducted by Gummesson (1999) view collaboration as a key element in creating an exchange between NPOs and their donors as well as their stakeholders. The author observed that the level of collaboration enhances the relationship and determine the extent to which it will last. This gives the organisation a leveraging opportunity in competing effectively as all NPOs compete to mobilise funds from limited sources. Also, several studies positioned trust at the centre of social exchange (Doney \& Cannon, 1997). Hence, NPOs who nurture trust could attract and secure the commitment of their donors and stakeholders (Feuk, 2011).

Generally, Perkins et al., (2009) confirmed that the theory was developed by Thibaut and Kelley (1959) to argue that most people base their assessment of relationship on the exchange. 
Therefore, donors and stakeholders will enter into a relationship with NPOs by assessing the costs and rewards associated with the relationship which can be viewed in terms of monetary costs, time, social commitment, and emotional investment (Bussell \& Forbes, 2006). However, the rewards are varied based on the expectation and satisfaction of the parties involved in the relationship (Cermak et al., 1994).

\subsection{Conceptual Model}

Figure 1 shows the proposed model for the study. It proposes a hypothesized model for the study to depict the critical factors that drive successful fundraising in NPOs. Internal factors are operationalised using organisational strategy, governance measures and internal resources, whiles external factors are operationalised using legislation or regulatory framework governing NGO operations, competition NPOs and prevailing economic conditions (Scott, 2014). It is thus hypothesised that the intra (strategy, governance, internal resources) and extra (legislation and economic condition) organisational factors directly impact on the success of fundraising. Thus, the conceptual model presents the critical factors that drive fundraising in emerging market organisational. The paper also moderates giving motives on the relationship between the internal and external factors and their impact on fundraising success.

Figure 1: Conceptual Framework of Factors Affecting the Fundraising Success of NPOs

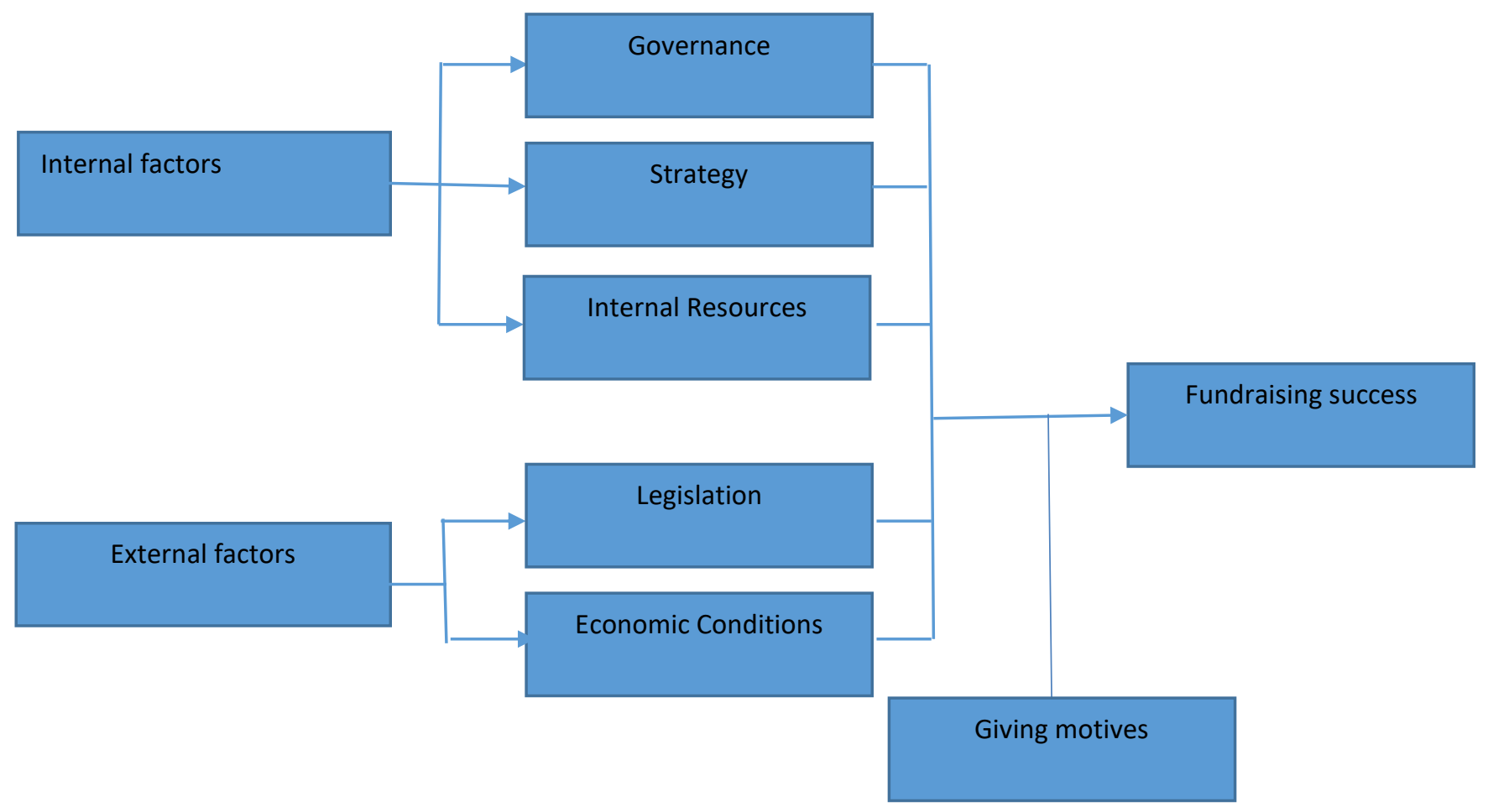

Source: Authors

\subsection{Hypothesis Development}

\subsubsection{External Factors}

Legislation: Scott (2014) suggests that all organisations are required to operate within a legislative framework. This is critical to the extra organisational factors that can influence the 
way funds are raised successfully through the effective utilization of resources. In most countries, the attention of governments is focused on firms meeting the legal requirements. However, NPOs face various challenges depending on their legal setups, type of funding available, the physical location of the organisation, and the permissible funding activities. All of these factors influence funding outcomes for NPOs. Based on this argument by Scott (2014), concerning how legislation influences successful fundraising by NPOs, this study hypothesises that:

H4: Legislation will positively impact on successful fundraising.

Economic conditions: This is one of the essential extra organisational fundraising-influencing factors that firms have no control over. NPOs, for instance, have virtually no control over factors such as economic instability (Scott, 2014; Burk, 2003). Burk (2003) asserted that the inherent challenges of economic sustainability have led most NPOs to become unmindful of their donors as not being donor-centred. The lack of control over economic factors means that the fundraising efforts of NPOs are subjected to unfavourable outcomes when economic conditions are dire and vice versa. (Scott, 2014; FIA, CSI \& PwC, 2009). It is thus hypothesised that:

H5: Prevailing economic conditions in Ghana will significantly impact on successful fundraising.

\subsubsection{The Moderating Role of Giving Motives}

The motive behind giving is very important in determining the success of any fundraising activity; there have been studies to examine the motivation behind the philanthropic giving behaviour. To increase the network of donors and encourage the practice of making charitable contributions, it is important to understand the reasons why people support causes through grassroots organisations.

Personal reasons: This relates to the congruence between the values/ideals of the giver and the NPO's or the desire for personal recognition. Donors whose personal interest are more aligned with that of an NPO tend to lend support. They are more likely to give to organisations that hold shared ideals and values (Kotler \& Lee, 2008). Also, some people are motivated to make donations due to the desire for personal recognition or other benefits such as public acknowledgement (Martens, 2015). Consequently, organisations often devote part of their resources to credit donors with gifts, plaques, or other signs of appreciation. This produces future commitments and repeats donations among such category of donors.

Altruistic reasons (public benefit): Some individuals simply donate to causes because of the internal satisfaction they derive from helping others (Powell \& Steinberg, 2006). Altruistic donor behaviours have long fascinated researchers. It seems such giving arises from a "natural willingness to help," bringing joy to the giver as a result of impacting someone else's life (ibid). Also, it helps to positively influence others, enjoy increased self-esteem and social status from giving (Wiekpking, 2009). Altruistic people are more inclined to give for public benefit when they are convinced that they will make "a lasting and tangible change as a result of their contribution" (Sims 2007, p.2). Such donors may approach organisations about the outcomes of their projects to determine the cost-effectiveness of a contribution (Barness, 2011). It follows that 
organisations who provide past measurable results and compelling information on the value of contributions are more likely to be successful in their fundraising efforts.

Supporting Family and Friends: People tend to donate to friends, family members, and others that they admire. $84 \%$ of charitable contributors prefer being asked to donate by people they know, since "a more personal solicitation [allows] the fundraiser to exert peer pressure on the donor" to engage in charitable causes (Jacobson \& Petrie, 2014). As a result, people with extensive social networks tend to be more charitable due to frequent donation requests from people in their networks (Wiepking \& Maas, 2009). With peer-to-peer solicitation, there is credibility from referrals from friends, family members, and colleagues. The social pressure of philanthropy also plays an influential role in determining whether and how much to give (Fritz, 2011). Based on the theoretical framework and the foregoing discussions, this paper hypothesises that:

H6: Giving motives moderate the positive relationship between the governance structure of NPOs and achieving success in fundraising

H7: Giving motives moderate the positive relationship between the organisational strategy of NPOs and achieving success in fundraising

H8: Giving motives moderate the positive relationship between the internal resources of NPOs and achieving success in fundraising

H9: Giving motives moderate the positive relationship between government policies and legislation and the success of NPOs regarding fundraising

H10: Giving motives moderate the positive relationship between the economic conditions and the success of NPOs regarding fundraising

\section{Procedures and Methods}

Research helps in finding answers to challenging societal questions and problems. To undertake effective and quality research, the paradigmatic and methodological positions are critical and such decisions need to be guided by scientifically grounded tenants of inquiry (Bryman, 2016; Caesar, 2016). The study aimed to identify the critical success factors underpinning successful fundraising among NPOs in Ghana. This paper adopts a quantitative research approach with a positivist design. The positivistic paradigm assumes an objective, quantitative approach. Sekaran and Bougie (2016) suggest a hypothetic-deductive approach beginning with problem definition, development of hypotheses, data collection and analysis including interpretation of data.

A survey was sent to 200 randomly sampled participants. The random sampling technique was preferred to achieve representativeness of the sample. In determining the sample size, care was taken to identify a reliable database of NPOs but this was unsuccessful given the lack of usable sources. As at January 2016, the population of registered local NPOs was estimated to be 5,000 and unregistered ones approximately 10, 000 (Adjei, Annor-Frempong \& Bosompem, 2016). Given the lack of clear figures on the population of NPOs, justification of the 200-sample size for the survey hinges on the recommendations of Rummel (1970) who was of the view that 
to get the required sample for a quantitative study, the item to respondent ratio should be 1:4, where 1 is the number of items in the questionnaire and 4 is the number of respondents. This is used when the total population is unknown. Based on this, the total number of items in the questionnaire was 48 and therefore the required sample was 192. The researchers, therefore, used a sample of 200 for the study in line with the specification of Rummel (1970).

The survey questionnaire sent to the 200 participants is structured. Frequently used for quantitative studies (Sekaran \& Bougie, 2016), structured questionnaires enable respondents to provide answers suitable for numerical analysis. Also, the responses are provided independently of the researcher (Kumar, 2011). Designing the data collection instrument was influenced by the study questions, hypotheses and conceptual model. The questionnaire was divided into two parts, namely Part I the Bio-Data and comprised demographic questions. Part II of the questionnaire consisted of 7 sections (A-G). Most measures in the questionnaire were chosen from those that had been employed in previous research. If the variables had satisfying quality in previous literature variables, they were adopted. Further, some measures were adopted. The measures of governance were adopted from the study of Ilyas and Rafiq (2012). Organisational strategy orientation had 7 items and was adapted from the study of Andrews, Beynon and Genc (2017). The study adopted a 5-item scales from Eniola and Entebang (2015) to measure legislation. The paper used a 7-item questionnaire sourced from Scott (2014) to measure giving motives.

Pilot testing of the survey instrument was done with thirty (30) respondents who were considered to have attributes representative of staffs of NPOs. In total 130 responses representing a $65 \%$ response rate was received after distribution of the questionnaire. The response was analysed using the Statistical Package for the Social Sciences (SPSS) v.23. The researcher made sure that the data was cleaned to make sure there were no missing variables that were likely to affect the output of the entire research work.

Also, ethical steps were taken to control for error and biases. The study respondents were given the assurance of anonymity and confidentiality of their responses; meaning the researcherparticipant relationship were not exploited ((Sekaran \& Bougie, 2016),). Respondents were not coerced into taking part in this study. Respondents were given the right to decide whether to participate without incurring any penalty ((Sekaran \& Bougie, 2016),). Respondents were approached and the purpose of the study explained to them and money was not offered to participants.

\section{Results and Findings}

\subsection{Quantitative Results}

\subsubsection{Background Information of Respondents}

In total 130 responses representing a $65 \%$ response rate was received after distribution of the questionnaire. Thus, the demographics of respondents are presented in Table 1. 
Table 1: Background Characteristics of Respondents

\begin{tabular}{|c|c|c|}
\hline Variables & Frequency & Percentage \\
\hline \multicolumn{3}{|l|}{ Gender } \\
\hline Male & 66 & 50.8 \\
\hline Female & 64 & 49.2 \\
\hline \multicolumn{3}{|l|}{ Age } \\
\hline Below 20 years & 5 & 3.8 \\
\hline 21-25 years & 5 & 3.8 \\
\hline 26-30 years & 39 & 30.0 \\
\hline 31-35 years & 46 & 35.4 \\
\hline $36-40$ years & 35 & 26.9 \\
\hline \multicolumn{3}{|l|}{ Position } \\
\hline CEO & 19 & 14.6 \\
\hline Manager & 48 & 36.9 \\
\hline Head of the unit & 32 & 24.6 \\
\hline Administrative officer & 31 & 23.8 \\
\hline \multicolumn{3}{|c|}{ Years worked in an organisation } \\
\hline Below 1 year & 19 & 14.6 \\
\hline $1-3$ years & 7 & 5.4 \\
\hline 4-7 years & 14 & 10.8 \\
\hline $8-10$ years & 43 & 33.1 \\
\hline Above 10 years & 47 & 36.2 \\
\hline \multicolumn{3}{|c|}{ Total employees in the organisation } \\
\hline Less than 20 & 5 & 3.8 \\
\hline $21-50$ & 33 & 25.4 \\
\hline $50-99$ & 92 & 70.8 \\
\hline \multicolumn{3}{|c|}{ Years of business existence } \\
\hline $0-1$ year & 12 & 9.2 \\
\hline $1-4$ years & 17 & 13.1 \\
\hline $5-9$ years & 57 & 43.8 \\
\hline $10-50$ years & 44 & 33.8 \\
\hline \multicolumn{3}{|l|}{ Level of Education } \\
\hline$P h D$ & 6 & 4.7 \\
\hline Masters & 55 & 42.6 \\
\hline Bachelors & 47 & 36.4 \\
\hline Diploma & 21 & 16.3 \\
\hline
\end{tabular}

Source: Authors Fieldwork 2017

Output: SPSS 23

Over half of the respondents were males $(50.8 \%)$, with $49.2 \%$ being females. This implies that the number of NPOs targeted had more males participating than females. The results do not, however, point to the underrepresentation of women in the local NPO sector. About $62.3 \%$ of respondents are between the ages of 31-40 years and the remaining ones below 31 years. Majority of the participants, representing $36.9 \%$ were managers followed by those holding positions as heads of business units (24.6\%), administrative officer (23.8\%) and CEO (14.6\%). This showed a 
majority of the participants held positions as managers and manageress's in their respective organisations. Also, 36.2\% have 10 years working experience with $33.1 \%$ having working experience of 10 years. This indicates that the majority of the participant surveyed had over eight years of experience with their respective companies.

The distribution of several employees of the organisations surveyed showed that over seventy per cent (70.8\%) of those employed were between 51-99 employees. More than twentyfive per cent $(25.4 \%)$ of the participants said they have between 21-50 employees while 3.8\% said that they have less than 20 employees. This showed a majority of the organisations have over fifty employees. The distribution of years of existence of organisation revealed that $43.8 \%$ have been in existence between 5-9 years, 33.8\% have been in existence between 10-50 years. This indicates that the majority of the organisations surveyed had long-standing experience with over nine years of existence.

\subsubsection{Measures and Validation}

The respondents were asked to indicate the extent to which they agree or disagree with statements about the dimensions of fundraising success in their organisations on a 5-point Likert scale with 1 , indicating strongly disagree and 5, indicating strongly agree. An exploratory factor analysis (EFA) (Caesar, 2016; Sekaran \& Bougie, 2016) was performed to determine common latent factors from the items used. The factor analysis yielded seven factors with the following names (Shown in Table 2): governance, strategy, legislation, economic condition, internal resources, giving motives and successful fundraising. The EFA was adopted to test the factorial validity of the scales. The Kaiser-Meyer-Olkin (KMO) measure of Sampling Adequacy was 0.801. The KMO variable exceeded the 0.60 benchmarks, confirming the suitability of the data for factor analysis. The Bartlett's Test of Sphericity (Bartlett 1954) also reached statistical significance with a Chi-Square (X2) of 3043.818 and a p-value of 0.001 . Table 2 also shows that seven components were extracted using the Principal Component Analysis (PCA) which explained 68.70 per cent of the total variance in the scale.

The reliability of the scales was examined by computing the Cronbach's alpha $(\alpha)$ (Cronbach, 1951). The reliability coefficients (in Table 3) for governance, strategy, legislation, economic condition, internal resources, giving motives and success fundraising were $.749, .772$, $.610, .876, .783, .904$, and .820 respectively. For all the constructs, the items have high loadings, with the majority above 0.60 , therefore, demonstrating convergent validity. Also, all items with a factor loading value of lower than 0.5 were dropped from the constructs to ensure unidimensionality.

Table 2: Exploratory Factor Analysis Results 


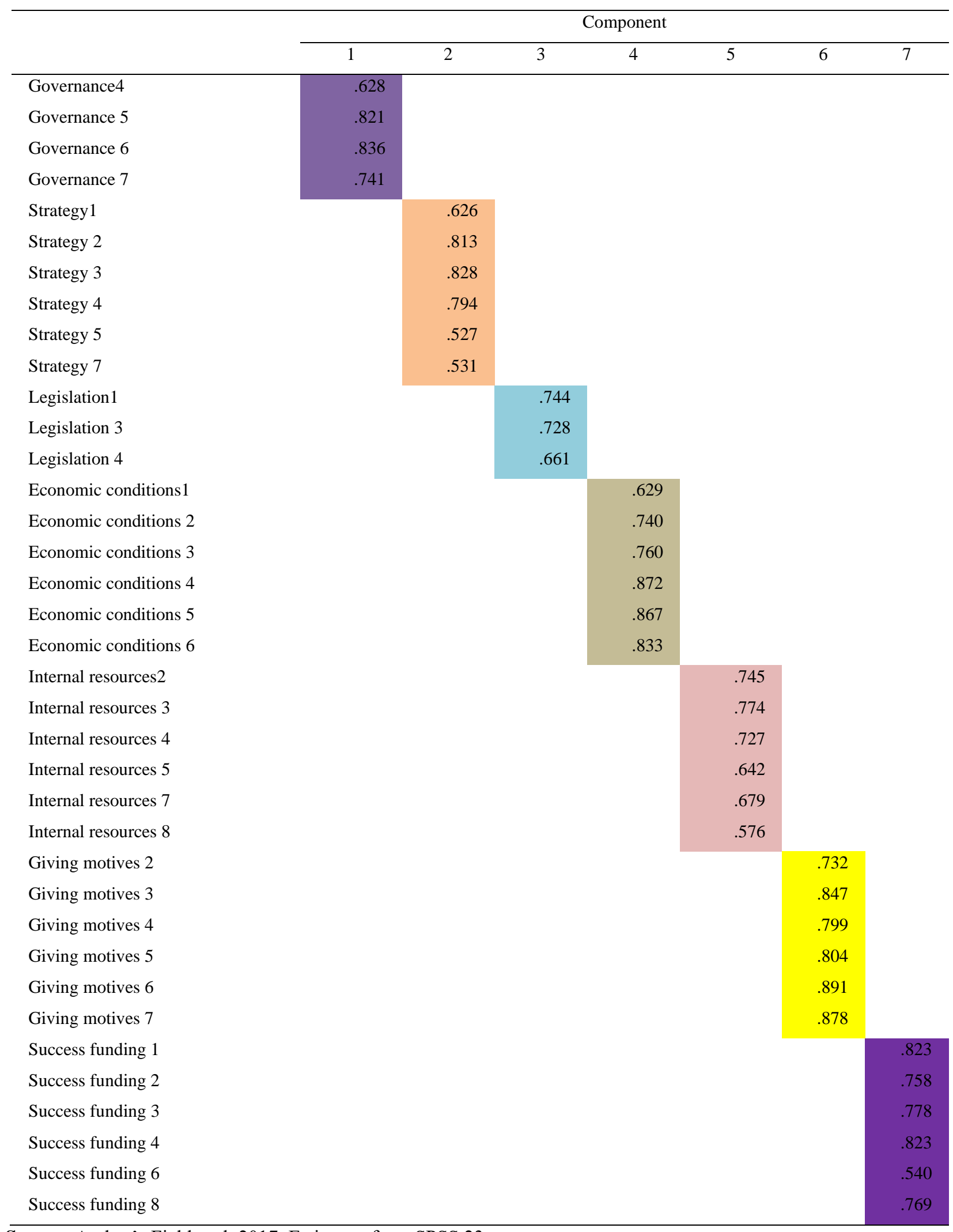

Source: Author's Fieldwork 2017, Estimates from SPSS 23

Table 3: Reliability Coefficients

\begin{tabular}{clcc}
\hline \multicolumn{2}{l}{ Scale } & Cronbach alpha Coefficient & No. of items \\
\hline 1. & Governance & .749 & 4
\end{tabular}


2. Strategy

3. Legislation

4. Economic conditions

5. Internal resources

6. Giving motives

.904

6

7. Success fundraising

.820

6

Source: Author's Fieldwork 2017, Estimates from SPSS 23

Table 4 above shows the descriptive and correlation results of the dependent and independent variables used for the study. Governance and successful fundraising were significantly correlated, $(r=.434, p<.01)$ just as strategy and successful fundraising $(r=.480, p<.01)$, legislation and successful fundraising $(r=.197, p<.01)$, economic conditions and successful fundraising $(r=.779, p<.01)$, internal resources and successful fundraising $(r=.428, p<.01)$ and giving motives and successful fundraising $(r=.822, p<.01)$. This means that all the independent variables were positively related to the dependent variable - successful fundraising.

Table 4: Descriptive Statistics and Correlations

\begin{tabular}{|c|c|c|c|c|c|c|c|}
\hline Variables & 1 & 2 & 3 & 4 & 5 & 6 & 7 \\
\hline 1. Governance ${ }^{\mathrm{a}}$ & 1 & $.787^{* * *}$ & $.461^{* *}$ & $.704^{* *}$ & $.412^{* *}$ & $.589^{* *}$ & $.434^{* *}$ \\
\hline 2. Strategy ${ }^{a}$ & & 1 & $.439^{* *}$ & $.639^{* *}$ & $.495^{* *}$ & $.531^{* *}$ & $.480^{* *}$ \\
\hline 3. Legislation ${ }^{\mathrm{a}}$ & & & 1 & $.190^{*}$ & $.637^{* *}$ & .124 & $.197^{*}$ \\
\hline 4. Economic conditions ${ }^{\mathrm{a}}$ & & & & 1 & $.284^{* *}$ & $.911^{* * *}$ & $.779^{* *}$ \\
\hline 5. Internal resources ${ }^{a}$ & & & & & 1 & .147 & $.428^{* *}$ \\
\hline 6. Giving motives ${ }^{b}$ & & & & & & 1 & $.822^{* *}$ \\
\hline 7. Successful fundraising ${ }^{\mathrm{b}}$ & & & & & & & 1 \\
\hline Mean & 3.85 & 4.52 & 4.46 & 3.63 & 4.49 & 3.77 & 4.35 \\
\hline Standard Deviation & .697 & .551 & .444 & .533 & .630 & .540 & .780 \\
\hline $\mathbf{N}$ & 130 & 130 & 130 & 130 & 130 & 130 & 130 \\
\hline
\end{tabular}

** $(p<.01),{ }^{*}(p<.05),{ }^{+}(p<.10)$

Source: Author's Fieldwork 2017, Estimates from SPSS 22

${ }^{\text {a }}$ The scale used for the measures of each construct was $1=$ strongly disagree and $5=$ strongly agree

${ }^{\mathrm{b}}$ The scale used for the constructs were $1=$ very low and $7=$ very high

$N=$ Population

Results of a hierarchical multiple regression done using successful fundraising as the dependent variable is presented in Table 5. Governance, strategy, legislation, economic conditions and internal resources were entered at stage one of the regressions to ascertain their effect on successful fundraising. Again, the independent variables, governance, strategy, legislation, economic conditions and internal resources with giving motives were entered at stage two. At stage three, the model included all the independent variables and their interaction effect with giving motives.

Table 5 shows the regression analysis of the effect of critical factors of fundraising on successful fundraising. Model 1 showed that the critical factors (governance, strategy, legislation, 
economic conditions and internal resources in the Model 2 contributed significantly to the regression model $F(6,123)=94.030, p<.001$ and resulted in $82 \%$ the variance in successful fundraising. The introduction of the interaction effect of giving motive with the independent variables (governance, strategy, legislation, economic conditions and internal resources) in Model 3 also contributed significantly to the regression model $F(11,118)=96.336, p<.001$ and increased the variance in successful fundraising by $7.90 \%$.

In Model 3 the factor governance was positively related to successful fundraising (b $=2.037, \mathrm{p}<.001)$. The strategy of the organisation was negatively related to successful fundraising $(\mathrm{b}=-1.768, \mathrm{p}<.001)$ just as legislation was not related to successful fundraising $(\mathrm{b}=$ $-.694, \mathrm{p}<.05)$. However, factors regarding economic conditions $(\mathrm{b}=.539, \mathrm{p}<.05)$ and internal resources $(b=1.346, p<.001)$ were positively related to successful fundraising. The interaction term showed that governance interaction with giving motives was negatively related to successful fundraising $(\mathrm{b}=-.281, \mathrm{p}<.001)$, strategy interaction with giving motives was positively related to successful fundraising ( $\mathrm{b}=.190, \mathrm{p}<.001$ ), legislation interaction with giving motives was positively related to successful fundraising $(b=.068, \mathrm{p}<.10)$ and internal resources interaction with giving motives was positively related to successful fundraising $(b=.232, p<.001)$. On the other hand, economic conditions interaction with giving motives was not related to successful fundraising $(\mathrm{b}=-.051, \mathrm{p}>.10)$.

Table 5: Regression Analysis of The Effect of Critical Factors of Fundraising on Successful Fundraising

\begin{tabular}{|c|c|c|c|c|}
\hline \multirow[b]{2}{*}{ Variables } & \multirow[b]{2}{*}{ Hypotheses } & \multicolumn{3}{|c|}{ Successful Fundraising } \\
\hline & & Model 1 & Model 2 & Model 3 \\
\hline \multicolumn{5}{|l|}{ Control variables } \\
\hline Constant & & $3.563(9.623)^{* * * *}$ & $-.107(-.333)$ & $5.854(4.871)^{* * *}$ \\
\hline Age firm & & $.075(.662)$ & $.012(.232)$ & $.033(.830)$ \\
\hline Size of firm & & $.030(.449)$ & $-.019(-.627)$ & $-.024(-1.060)$ \\
\hline \multicolumn{5}{|l|}{ Independent variables } \\
\hline Governance & $H_{1}$ & & $-.357(-3.877)^{* *}$ & $2.037(4.931)^{* * * *}$ \\
\hline Strategy & $\mathrm{H}_{2}$ & & $.018(.169)$ & $-1.768(-3.890)^{* * *}$ \\
\hline Legislation & $\mathrm{H}_{3}$ & & $-.101(-1.420)$ & $-.694(-2.124)^{*}$ \\
\hline Economic conditions & $\mathrm{H}_{4}$ & & $.095(.754)$ & $.539(2.538)^{*}$ \\
\hline Internal resources & $\mathrm{H}_{5}$ & & $.571(8.080)^{* * * *}$ & $1.346(4.910)^{* * *}$ \\
\hline Giving motives & & & $.759(8.600)^{* * *}$ & $.440(5.631)^{* * *}$ \\
\hline \multicolumn{5}{|l|}{ Interaction effects } \\
\hline Governance $\times$ Giving motives & $\mathrm{H}_{6}$ & & & $-.281(-5.191)^{* * * *}$ \\
\hline Strategy $\times$ Giving motives & $\mathrm{H}_{7}$ & & & $.190(3.925)^{* * *}$ \\
\hline Legislation $\times$ Giving motives & $\mathrm{H}_{8}$ & & & $.068(1.686)^{+}$ \\
\hline Economic conditions $\times$ Giving motives & $\mathrm{H}_{9}$ & & & $-.051(-1.516)$ \\
\hline Internal resources $\times$ Giving motives & $\mathrm{H}_{10}$ & & & $.232(6.800)^{* * * *}$ \\
\hline$R^{2}$ & & .050 & .821 & .900 \\
\hline Adjusted $R^{2}$ & & -.011 & .812 & .890 \\
\hline
\end{tabular}




\begin{tabular}{lccc}
\hline$\Delta R^{2}$ & & .110 & .079 \\
F statistic & $.315^{* * *}$ & $94.030^{* * *}$ & $96.336^{* * *}$ \\
Degrees of freedom & $2 / 127$ & $6 / 123$ & $11 / 118$ \\
\hline
\end{tabular}

${ }^{+} p<0.10 .,{ }^{*} p<0.05 .,{ }^{* *} p<0.01 .,{ }^{* * *} p<0.001$.

Note: Unstandardized regression coefficient was reported (t-values are in parentheses)

\subsubsection{Hypotheses Summary}

Table 6 present the results of the hypotheses tests assessed using the sign of the various coefficients and their 5 per cent significance level. The regression results showed that the strategy of the organisation was negatively related to the success in fundraising. Thus, the hypothesis that there is a significant positive relationship between the organisational strategy of NPOs and success in fundraising was not supported.

Hypothesis 2 stated that the efficiency of the board as governing body will significantly impact on successful fundraising. The results of the regression analysis revealed that the governance structure was positively related to the success in fundraising and significant. Thus hypothesis 2 was supported. The regression results revealed that internal resources were positively related to successful fundraising. Thus hypothesis 3 was supported.

The regression results showed legislation was negatively related to successful fundraising. This means that the hypothesis 4 was not supported. The regression results showed economic conditions was positively related to successful fundraising. This means that hypothesis 5 was supported. Table 6 provides a summary on the 10 hypotheses in the studying indicating which one ones were accepted and rejected.

Table 6: Summary of Statistical Results

\begin{tabular}{|c|c|c|}
\hline Hypothesis & $\begin{array}{l}\text { Expected } \\
\text { sign }\end{array}$ & $\begin{array}{l}\text { Empirical } \\
\text { conclusions }\end{array}$ \\
\hline $\begin{array}{l}\text { H1: There is a positive relationship between the strategy adopted by non- } \\
\text { profit organisations and successful fundraising. }\end{array}$ & + & Not supported \\
\hline $\begin{array}{l}\text { H2: The efficiency of the board as a governing body significantly impact } \\
\text { on successful fundraising. }\end{array}$ & + & Supported \\
\hline $\begin{array}{l}\text { H3: The effective utilization of internal resources significantly impacts on } \\
\text { successful fundraising. }\end{array}$ & + & Supported \\
\hline H4: Legislation positively impact on successful fundraising & + & Not Supported \\
\hline $\begin{array}{l}\text { H5: The prevailing economic conditions in Ghana significantly impact on } \\
\text { successful fundraising }\end{array}$ & + & Supported \\
\hline $\begin{array}{l}\text { H6: Giving motives moderate the positive relationship between the } \\
\text { governance structure of NPOs and the success in fundraising }\end{array}$ & + & Not supported \\
\hline $\begin{array}{l}\text { H7: Giving motives moderate the positive relationship between the } \\
\text { organisational strategy of NPOs and the success in fundraising }\end{array}$ & + & Supported \\
\hline $\begin{array}{l}\text { H8: Giving motives moderate the positive relationship between government } \\
\text { policies and legislation and the success of INGOs regarding fundraising }\end{array}$ & + & Supported \\
\hline
\end{tabular}




H9: Giving motives moderate the positive relationship between the
economic conditions and the success of NPOs regarding fundraising
$\begin{aligned} & \text { H10: Giving motives moderate positive relationship between the internal } \\ & \text { resources of NPOs and the success in fundraising }\end{aligned}$

\section{Discussion, implications and conclusion}

\subsection{Discussion, Practical Implications and Conclusion}

\subsubsection{Credibility and aAccountability}

This study aimed to identify critical factors that influence fundraising success among NPOs from an emerging market perspective. Inability to raise enough funds to execute their mandate is a key challenge confronting NPOs in such markets. The study results showed that factors such as the organisational objective, human resource capability, credibility, location and accountability are influential in driving successful fundraising. Hence, NPOs need to critically consider these factors to effectively raise funds for their operations. For instance, organisational objectives of the NPOs need to be clearly outlined on how they intend to achieve their corporate vision; as any form of ambiguity undermines fundraising efforts. Also, NPOs must be wellpositioned to attract and retain a highly-skilled workforce to bolster their ability to successfully raise funds. Such staff must have specific skills on grant writing and sourcing for donor funds.

The credibility of the NPOs also critical to the success of fundraising raising activities. Without a good credit rating, sustaining the NPO becomes more difficult as donors tend to withhold funds from less credible organisations. NPOs must, therefore, work at building an image of reliability and have good track records to assure donors that funds given will be misappropriated. Accountability dovetails into building a credible image for an organisation. Similarly, NPOs which fail to be accountable to their donors and other stakeholders concerning donated funds are less likely to be successful in their fundraising attempts. Consequently, accountability should be demonstrated through the submission of reports for projects undertaken. This builds the confidence of such donors in the NPO and thus encourage them to continually fund the NPO's activities.

\subsubsection{Structures}

The study also sought to identify structures that could help the fundraising efforts of NPOs. Structures are important to the success of every organisation. The study results revealed that NPOs are likely to be successful at fundraising contingent on the institution of proper structures. Common structures for NPOs include the use of fundraising committees, media, the board of directors, collaboration, organisational/project plan need to be in place. The presence of a board of directors is necessary to steer the affairs of the NPOs within appropriate governance structures to build reputation clout. This in addition to the use of prominent persons in the society as board members could positively influence fundraising outcomes. Also, exploiting the power of the media (print, electronic and social) to propagate the activities of NPOs could help secure funds from donors. NPOs must also have effective communication sections that will also be 
speaking to society on their activities and plans. Forming fundraising committees at the suborganisational level is also part of the structures needed by NPOs to successfully raise funds.

\subsubsection{Obstacles that Limit Effective Fundraising}

The third objective of the study is to identify the obstacles that limit effective fundraising among NPOs from emerging markets such as Ghana. The obstacles identified include identical and competing NPOs, bureaucracy, fatigue, intra-conflicts, fraudsters, lack of funds/research team, poor accountability skills, among others. These factors undermine the fund-raising efforts of NPOs prompting the need for appropriate measures to curtail their negative impact on fundraising. Notwithstanding, a major obstacle to successful fundraising among NPOs in emerging markets is a fraud. This is when individuals and institutions deliberately use the names of credible organisations and sometimes key personalities to fraudulently solicit funds. Others use awful photographs of persons and humanitarian organisations to dupe persons and institutions both locally and abroad. This has made it relatively difficult to isolate the good organisations from the bad ones which in turn affect the operations of most NPOs.

\subsubsection{The Internal vs. External Factors of Successful Fundraising in NPOs?}

Results from the regression analysis showed that economic conditions and legislation were the significant predictors of successful fundraising. Hence for NPOs in emerging markets to successfully raise funds, they must operate within a clear regulatory framework where policymakers need to abrogate laws that negatively impact fundraising efforts of NPOs. The economic conditions of every country play a critical role in the survival or growth of businesses in that particular country. Burk (2003) asserted that the inherent challenges of economic sustainability have made most NPOs to become unmindful of their donors, thus not being donorcentred. Hence the economic conditions of a country either impact positively or negatively on the fundraising activities of NPOs. When the economy is strong and good, it creates a conducive environment for more donors to support the activities of NPOs. This confirms a study by Scott (2014) which found economic conditions as a key factor to the success of fundraising for NPOs.

\subsection{Direction for Future Study}

Considering the size of the number of NPOs, the sample size should have been larger than the present number. This constitutes a key limitation that future researchers may work to overcome. Hence the current study could be replicated with larger sample size. Also, future research should examine the moderating role of economic conditions on successful fundraising among NPOs in emerging markets.

\section{References}

[1] Abubakar, M. M., \& Mokhtar, S. S. M. (2015). Relationship marketing, long-term orientation and customer loyalty in higher education. Mediterranean Journal of Social Sciences, 6(4), 466.

[2] Adjei, D. K. A., Annor-Frempong, F., \& Bosompem, M. (2016). Use of social networking websites among NGOs in the Greater Accra Region of Ghana. Public Relations Review, 42(5), 920-928. 
[3] Ahmed, S., \& Potter, D. M. (2006). NGOs in international politics (Vol. 48). Bloomfield, CT: Kumarian Press.

[4] Anderson, E. W., Fornell, C., \& Mazvancheryl, S. K. (2004). Customer satisfaction and shareholder value. Journal of Marketing, 68(4), 172-185.

[5] Aryee, T. E. (2015). Corporate governance, fundraising and operational efficiency of non-governmental organizations in Ghana (Doctoral dissertation, University of Ghana).

[6] Bartlett, M. S. (1954). A note on the multiplying factors for various $\chi 2$ approximations. Journal of the Royal Statistical Society. Series B (Methodological), 16(2) 296-298.

[7] Barnes, S (2011). In with the new: Fundraising in 2011. Non-profit Consulting and Talent Management. Campbell \& Company. Web. 24 Aug. 2011. $<$ http://www.campbellcompany.com/articles/>.

[8] Batti, R. C. (2014). Challenges facing local NGOs in resource mobilization. Humanities and Social Sciences, 2(3), 57-64.

[9] Bendell, J. (2017). Terms for endearment: Business, NGOs and sustainable development. Routledge.

[10] Bennett, R. (2005). Competitive environment, market orientation, and the use of relational approaches to the marketing of charity beneficiary services. Journal of Services Marketing, 19, 453-469.

[11] Bennett, R., \& Sargeant, A. (2005). The nonprofit marketing landscape: guest editors' introduction to a special section. Journal of Business Research, 58(6), 797-805.

[12] Bhagwati, J. (2004). In defence of globalization: With a new afterword. Oxford University Press.

[13] Britton, R. A. (2008). Making disclosure regulation work in the non-profit sector. U. Ill. L. Rev., pp. 437-458.

[14] Brownell, G., \& Basham, R. (2017). NGO strategy toward the reintegration of child soldiers in Liberia, Africa: An online survey of services, roles, and activities. International Social Work, 60(5), 1074-1086.

[15] Burk, P. (2003). Donor-centred fundraising. Burk \& Associates Ltd.

[16] Bussell, H., \& Forbes, D. (2006). Developing relationship marketing in the voluntary sector. Journal of Nonprofit \& Public Sector Marketing, 15(1/2), 151-174.

[17] Bryman, A. (2016). Social research methods. Oxford University Press.

[18] Caesar, D. L. (2016). The global shortage of ship officers: an investigation of the complexity of retention issues among Australian seafarers (Doctoral dissertation, University of Tasmania), Launceston, Australia. 
[19] Cermak, D.S.P., File, K.M., \& Prince, R.A. (1994). A benefit segmentation of the major donor market. Journal of Business Research, 29(2), 121-130.

[20] Cronbach, L. J. (1951). Coefficient alpha and the internal structure of tests. Psychometrika, 16(3), 297-334.

[21] Doney, P. M., \& Cannon, J. P. (1997). An examination of the nature of trust in buyerseller relationships. the Journal of Marketing, 35-51.

[22] Drezner, N. D. (2009). Why give?: Exploring social exchange and organisation identification theories in the promotion of philanthropic behaviours of AfricanAmerican millennials at private-HBCUs. International Journal of Educational Advancement, 9(3), 147-165.

[23] Edwards, M., \& Hulme, D. (2014). Non-governmental organisations-performance and accountability: Beyond the magic bullet. Routledge.

[24] Ferguson, M. A. (1984). Building theory in public relations. Interorganizational relationships as a public relations paradigm. Paper presented to Association for Education in Journalism and Mass Communication, Gainesville, FL.

[25] Feuk, J. (2011). A Relationship with benefits: Relationship marketing in Non-profit Organisations in South Africa.

[26] Frey, B. S. (2008). Outside and inside competition for international organizations - from analysis to innovations. The Review of International Organizations, 3(4), 335-350.

[27] Fritz, J. (2011). The Science of giving - A Review charitable giving through the eyes of social scientists. Non-profit Charitable Organisations. About.com. Web. 15 Aug. 2017. < http://nonprofitnon-profit.about.com/od/fundraising/fr/The-Science-OfGiving-A-Review.htm>.

[28] Grönroos, C. (2006). On defining Marketing: Analysis of the updated AMA definition and an alternative. Svenska Handelshögskolan, 514.

[29] Gummesson, E. (1999). Total Relationship Marketing. The Chartered Institute of Marketing.

[30] Gyamfi, P. (2010). Financing local non-governmental organisations in Ghana: Issues and challenges (Doctoral dissertation, Department of Planning, Kwame Nkrumah University of Science and Technology).

[31] Hanson, J. H. (1997). Strategic management and fundraising: A planning model for resource development in the non-profit organisation. International Journal of Nonprofit and Voluntary Sector Marketing, 2(4), 315-323.

[32] Jacobson, S., \& Petrie, R. (2014). Favour trading in public good provision. Experimental Economics, 17(3), 439-460.

[33] Klein, K. (2009). Reliable fundraising in unreliable times: What good causes need to know to survive and thrive, San Francisco, CA, Jossey-Bass. 
[34] Kotler, P., \& Lee, N. (2008). Corporate social responsibility: Doing the most good for your company and your cause. John Wiley \& Sons.

[35] Kumar, R. (2011). Research methodology: A step-by-step guide for beginners. $3^{\text {rd }}$ edition. Sage Publication.

[36] Lekorwe, M., \& Mpabanga, D. (2007). Managing non-governmental organizations in Botswana. The Public Sector Innovation Journal, 12(3), 1-18.

[37] Lindahl, W. E., \& Conley, A. T. (2002). Literature review: Philanthropic fundraising. Non-profit Management and Leadership, 13(1), 91-112.

[38] Marten, C. (2015). Understanding Donor Motivation and Behaviour Among MiddleClass Americans (Doctoral dissertation, University of Waikato).

[39] Mitlin, D., Hickey, S., \& Bebbington, A. (2007). Reclaiming development? NGOs and the challenge of alternatives. World Development, 35(10), 1699-1720.

[40] Morgan, R. M., \& Hunt, S. D. (1994). The commitment-trust theory of relationship marketing. The Journal of Marketing, 20-38.

[41] Nah, S., \& Saxton, G. D. (2013). Modelling the adoption and use of social media by nonprofit organizations. New Media \& Society, 15(2), 294-313.

[42] Najam, A. (1996). NGO accountability: A conceptual framework. Development Policy Review, 14(4), 339-354.

[43] Nyanumba, P. M. (2018). Influence of financial sustainability strategies on performance of counties in Kenya (Doctoral dissertation, JKUAT).

[44] Okorley, E. L., \& Nkrumah, E. E. (2012). Organisational factors influencing the sustainability of local non-governmental organisations: Lessons from a Ghanaian context. International Journal of Social Economics, 39(5), 330-341.

[45] Perkins, A., Algren, M., \& Eichhorn, K. C. (2009). The use of integrated marketing communications by US non-profit Organisations. In Proceedings of the $12^{\text {th }}$ Annual International Public Relations Conference: Research that Matters to the Practice, Miami - Florida, 518-533.

[46] Powell, W. W., \& Steinberg, R. (Eds.). (2006). The non-profit sector: A research handbook. Yale University Press.

[47] Sargeant, A. (2016). Relationship fundraising: Where do we go from here? Volume 1 review of theory from relationship marketing. Plymouth: Centre for Sustainable Philanthropy, Plymouth University.

[48] Sargeant, A., \& Jay, E. (2002). The role of funders in non-profit merger activity: Implications for charity fundraising and marketing practice. Journal of marketing management, 18(9-10), 953-970. 
[49] Sargeant, A., \& McKenzie, J. (1998). A lifetime of giving: An analysis of donor lifetime value. Charities Aid Foundation.

[50] Scott, M. A. (2014). Organizational factors that drive fundraising effectiveness in Australian health charities (Doctoral dissertation, Queensland University of Technology).

[51] Sekaran, U., \& Bougie, R. (2016). Research methods for business: A skill-building approach. John Wiley \& Sons.

[52] Sims, S (2007). Why do people donate to charitable causes? fundraiser ideas for nonprofit organisations | Step by step fundraising ideas. Step-by-Step fundraising, Web. 29 Aug. 2011. <http://stepbystepfundraising.com/why-do-people-donate-to-charitablecauses>

[53] Taylor, T. K., Muwowo, F., \& Phiri, Z. L. (2018). Constraining factors in realizing strategic plan objectives by local authorities in Zambia: Case of Kitwe City Council. Strategic Public Management Journal, 4(7), 98-119.

[54] Thibaut, J.W., \& Kelley, H.H. (1959). The Social Psychology of Groups. John Wiley \& Sons, Inc.

[55] Unicef. (2011). UNICEF annual report 2010. UNICEF.

[56] Waters, R. D., Friedman, C. S., Mills, B., \& Zeng, L. (2011). Applying Relationship Management Theory to Religious Organisations: An Assessment of Relationship Cultivation Online. Journal of Communication \& Religion, 34(1), 88-104.

[57] Weir, L., \& Hibbert, S. (2000). Building donor relationships: An investigation into the use of relationship and database marketing by charity fundraisers. The Service Industries Journal, 20(2), 114-132.

[58] Wiepking, P., \& Maas, I. (2009). Resources that make you generous: Effects of social and human resources on charitable giving. Social Forces, 87(4), 1973-1995.

[59] Zheng, Y. (2012). A case study examination into how charities enhance fundraising effectiveness through managing relationship with donors and beneficiaries. 